\title{
Evaluation of Carrot Quality Using Visible-Near Infrared Spectroscopy and Multivariate Analysis
}

\author{
Ahmed M. Rady ${ }^{1,3}$, Shinta Sugiharto ${ }^{2} \&$ Akinbode A. Adedeji ${ }^{1}$ \\ ${ }^{1}$ Department of Biosystems and Agricultural Engineering, University of Kentucky, Lexington, KY40546, USA \\ ${ }^{2}$ Indonesia International Institute for Life Sciences, Jakarta Timur, Indonesia \\ ${ }^{3}$ Department of Agricultural and Biosystems Engineering, Alexandria University, Alexandria, Egypt \\ Correspondence: Akinbode A Adedeji, Department of Biosystems and Agricultural Engineering, University of \\ Kentucky, Lexington, KY40546, USA. Tel: 1859-218-4355. E-mail: akinbode.adedeji@uky.edu
}

Received: April 15, 2018

Accepted: May 4, 2018 Online Published: May 24, 2018

doi:10.5539/jfr.v7n4p80

URL: https://doi.org/10.5539/jfr.v7n4p80

\begin{abstract}
Carrot has a relatively high content of Vitamin $\mathrm{C}$ and it is a major source of natural carotenoids. However, carrot has a short shelf-life and is better consumed fresh. A quick assessment of its quality attributes is important to preserving its freshness. The objective of this study was to apply Vis-NIR spectroscopy to noninvasively assess and predict the various quality attributes of carrot (cv. Nectar), namely color $\left(L^{*} a^{*} b^{*}\right)$, moisture content (MC), total soluble solids (TSS), firmness, Vitamin C, and $\beta$-carotene. Two spectroscopic sensors $(400-1,000 \mathrm{~nm}$ and $900-1,700 \mathrm{~nm}$ ) were utilized and samples included whole root and $25.4 \mathrm{~mm}$ thick sliced disc. The best prediction models using partial least squares regression yielded correlation coefficient, $r$, and ratio of performance to deviation or $\mathrm{r}(\mathrm{RPD})$ of $0.50(0.73), 0.84(0.88), 0.86(2.07), 0.69(0.66), 0.97(1.44), 0.90(1.49), 0.47(1.47)$, and 0.92(1.76) for color indices, $L^{*} a^{*} b^{*}$, firmness, MC, TSS, Vitamin C, and $\beta$-carotene, respectively. However, using only the wavelengths selected by interval partial least squares, the r(RPD) values for the aforementioned attributes improved and are presented as follows: 0.92(1.97), 0.96(2.83), 0.98(5.85), 0.99(6.65), 0.98(3.91), 0.99(5.93), 0.98(4.16), and 0.98(4.43), respectively. Generally, Vis-NIR region had higher prediction performance than NIR region, and whole roots had similar prediction performance as sliced samples. This study shows that rapid determination of quality parameters of carrot is possible through non-destructive Vis-NIR sensing, which could be useful for quality tracking during carrot supply chain. Moreover, results of this study could be improved using a larger sample size.
\end{abstract}

Keywords: carrot, carotenoids, PLSR, Vitamin C, Vis-NIR spectroscopy, IPLS

\section{Introduction}

Carrot (Daucus carota L.) is an important root vegetable crop and a major source of essential micronutrients such as Vitamins A and C. Carrot production worldwide has been on the increase since 1961. The world production of carrot in 2014 was 83,840 million tons, while the US production during the same period was 1,440 million tons obtained from 34,660 hectares (Food and Agriculture Organization [FAO], 2017). Most carrot roots have orange-like color, however, other colors such as purple, red, and yellow can also be found in the markets (Becaro et al., 2016). Carrot roots, either in fresh or frozen conditions, provide considerable amounts of Vitamin $\mathrm{C}$ (ascorbic acid) and phenolic compounds that act as antioxidants (i.e. anthocyanin) (Alasalvar, Al-Farsi, Quantick, Shahidi, \& Wiktorowicz, 2005; Klaiber, Baur, Koblo, \& Carle, 2005; Favell, 1998). Additionally, carrot is a rich source of provitamin A and more specifically $\alpha$ and $\beta$-carotene and carotenoids (lutein, lycopene) depending on the root color (Berger, Küchler, Maaßen, Busch-Stockfisch, \& Steinhart, 2008). Processed carrot foods are among the basic meals for infants and young children (Seidel et al., 2015). Consumption of carrot is also linked to decreased risk of prostate cancer and has the potential to improve heart and liver functionality and consequently protect against cardiovascular diseases (Xu et al., 2014; Potter, Foroudi, Stamatikos, Patil, \& Deyhim, 2011; Nicolle et al., 2003). The production of $\alpha$-tocopherol- $\beta$-carotene (ATBC) drinks, also called carotenoid drinks, depends on carrot juice as a natural source of provitamin A (Simon et al., 2008; Demir, Acar, $\&$ Bahçeci, 2004). Quality attributes of carrots that are important indicators of stability and support systems for human health include absence of bruises, color, total soluble solid (TSS), provitamin A especially $\beta$-carotene and carotenoids, Vitamin C, and firmness (Simon et al., 2008; Demir et al., 2004). Carrots are usually consumed as 
fresh, frozen or as juice. Fresh-cut packaged carrots have gained a lot of interest since 1980's (Becaro et al., 2016). The ability to quickly determine carrot's quality attributes along the supply chain is very important to preserving its freshness. Therefore, it is essential to develop systems for quick quality control of carrot, beyond the time-consuming laboratory techniques.

The application of noninvasive techniques for evaluating quality attributes of agricultural products has gained significant attention in applied research and the production industry lately (Porep, Kammerer, \& Carle, 2015). Spectroscopic devices especially those within near-infrared (NIR), are among the early technologies used in monitoring the quality of agricultural commodities. NIR systems are fast, nondestructive, reliable, cost effective, versatile, and require minimal sample preparation compared to other analytical methods (Burns \& Ciurczak, 2007). Norris (1986) was one of the first studies that applied NIR in the agricultural domain studied the feasibility of using NIR spectral absorption for rapid measurement of fat and moisture levels in samples of meat emulsions. A correlation was found between the optical density and moisture and fat content with a standard error of 2.1 and $1.4 \%$ for moisture and fat, respectively. Since then, there has been extensive work on investigating the potential of NIR systems in detecting chemical constituent especially with the significant improvement in light-fiber optics and detection designs along with the development of effective chemometrics algorithms (Siesler, 2008). Estimation of various quality traits of carrot was investigated using rapid and/or noninvasive techniques. Zude, Birlouez-Aragon, Paschold, \& Rutledgem (2007) investigated the utilization of visible Vis-NIR technique to measure carrot quality attributes at different storage and handling conditions. They estimated sugar, $\alpha$ - and $\beta$-carotene content. Results showed that the levels of the standard error of cross validation (SECV) for sugar models were 15.4, 4.6, and 2.3\% for sucrose, glucose, and fructose, respectively. Whilst the SEVC value for $\alpha$ - and $\beta$-carotene content models were <1\%. In another study conducted by Quilitzsch, Baranska, Schulzm, \& Hoberg (2005), where they used UV-Vis, NIR and IR spectroscopic sensors (FT-NIR spectrometer) within $833-2,500 \mathrm{~nm}$, where they evaluated $\alpha$ and $\beta$-carotene, the total carotenoids, and dry matter. The cross-validation results showed high values of the coefficient of determination $\left(R^{2}\right)$ of $0.70-0.96$. In the same study, fructose, glucose, sucrose, and the total sugar were also estimated using FTIR in the attenuated total reflection (ATR) mode and the best models had $R^{2}$ values of 0.62-94. It is important to state that results obtained in the previous two studies were based only on a training data set using cross validation, and no separate test-sets were used to evaluate the calibration models. Other methods tested to predict carrot quality are Raman spectroscopy (Krähmer, Böttcher, Rode, Nothnagel, \& Schulz, 2016; Lawaetz et al., 2016; Schulz, 2014; Keller, Löchte, Dippel, \& Schrader, 1993), nuclear magnetic resonance (NMR) (Schneider, 1997), and fluorescence spectroscopy (Ahmad, Sahar, \& Hitzmann, 2017). The major drawback to these methods is that they produce significant amount of data that would not allow their application for quick online/inline assessment. Our objectives in this research were to determine the effectiveness of using Vis-NIR diffuse reflectance technology and multivariate statistical analysis to evaluate several quality attributes of carrot roots, and also obtain the most effective wavelengths associated with such quality parameters.

\section{Materials and Methods}

\subsection{Samples Preparation}

Organic carrot (cv. Nectar) used for the study was bought from a local certified organic farm in Lexington, Kentucky, USA. Carrot samples were cleaned from dirt and decayed or bruised roots were discarded. Samples were then stored at $4{ }^{\circ} \mathrm{C}$ and a relative humidity of 95\% (Luo, Suslow, \& Cantwell, 2016). An initial sampling with six replicates was conducted after receiving the samples. Further sampling then took place over a period of 8 weeks in a weekly basis. After the eighth week, the stored samples showed severe shriveling and started to sprout. The purpose of studying stored sample was to create a relatively wide range of the measured quality attributes and consequently obtain more conclusive prediction models and stimulate the real cases for storage. A total of 30 carrot roots were used, which included whole intact roots and sliced samples (discs). Three replicates were tested at each sampling time. After scanning the whole root 2 times with $180^{\circ}$ apart, three slices were cut from the stem end, root end and in the middle. Each slice was approximately $25.4 \mathrm{~mm}$ thick and both sides of each slice were scanned. CIE $L^{*} a^{*} b^{*}$ color parameters were first measured for each sample followed by measuring the firmness. Samples were then crushed and each of total soluble solids (TSS), moisture content, Vitamin $\mathrm{C}$, and $\beta$-carotene was then estimated. To account for the spatial variation for each constituent, several readings were acquired for each replicate. In the case of color and firmness, six readings were acquired. Whereas, in the case of moisture and $\beta$-carotene, two readings were obtained. Finally, three readings were obtained for TSS and Vitamin C. The average of such readings was then recorded. Fig. 1 shows a schematic diagram for the sequence of experiments. 


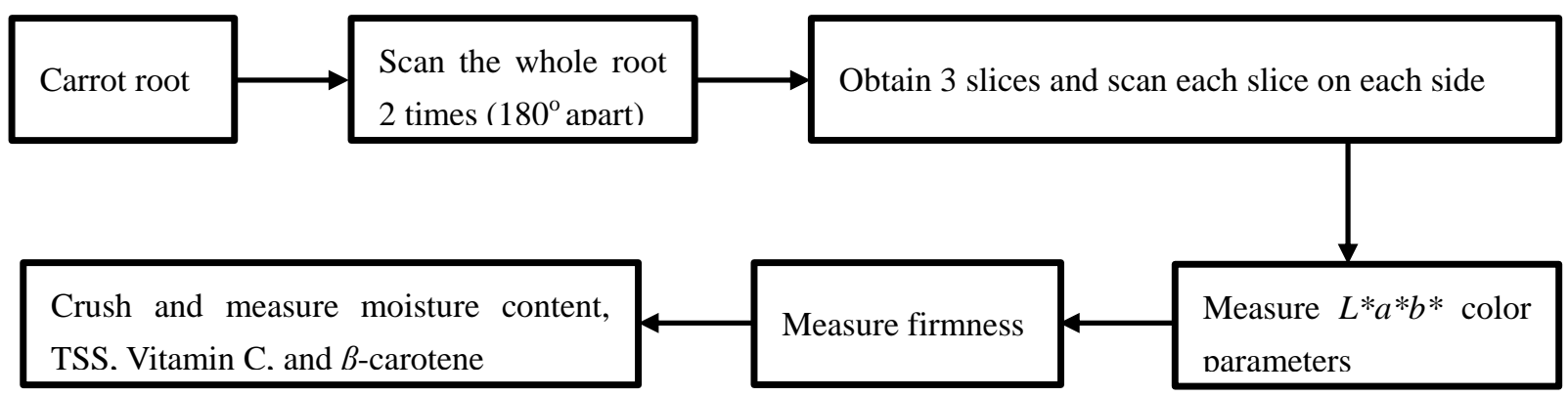

Figure 1. Schematic diagram for the experiment sequence for evaluating carrot quality using Vis-NIR spectroscopy

\subsection{Optical System}

The optical system used to acquire spectral information of carrot roots is a Vis-NIR spectroscopic system operating in the diffuse reflectance mode. The system, as shown in the schematic diagram in Fig. 2, consists of two different spectrometers. The first spectrometer (model no. HR4000, Ocean Optics Inc., Dunedin, FL, USA) detects light in the Vis-NIR region between $195-1,100 \mathrm{~nm}$ and has, a 3,648-element linear silicon CCD array with a spectral resolution of 0.02-8.4 $\mathrm{nm}$ (full width high maximum or FWHM), and signal to noise ratio (SNR) of up to 300:1. The second spectrometer (model no. NIRQUEST512 Ocean Optics Inc., Dunedin, FL, USA) works in the NIR region of 900-1,700 nm and has an InGaAs linear array detector with optical resolution of 3.1 $\mathrm{nm}$ (FWHM), SNR of up to 3000:1. The light source is a tungsten halogen lamp with a nominal output power of $20 \mathrm{~W}$ (model no. HL-2000-HP-FHSA, Ocean Optics Inc., Dunedin, FL, USA). The integrated reflectance probe (model no. QR400-7-Vis-NIR, Ocean Optics Inc., Dunedin, FL, USA) has $400 \mu \mathrm{m}$ diameter with 6 illuminating fibers around two read fibers to obtain the spectrum for each spectrometer. The integrated probe is comprised of a fiber cable receiving the incident light and two output fibers using splitter fiber (SPLIT400-Vis-NIR, Ocean Optics Inc., Dunedin, FL, USA). The reflectance measurement for each sample was calibrated by the spectrolan diffuse reflectance standard disc (WS-1-SL, Labsphere, Inc., North Sutton, NH, US). The relative reflectance was then calculated as follows:

$$
\text { Relative reflectance }=\frac{I_{s}-I_{b}}{I_{r}-I_{b}}
$$

where $I_{s}$ is the intensity of reflected light for sample, $I_{r}$ is the intensity of reflected light for the reflectance standard disc, and $I_{b}$ is the intensity of reflected light for background.

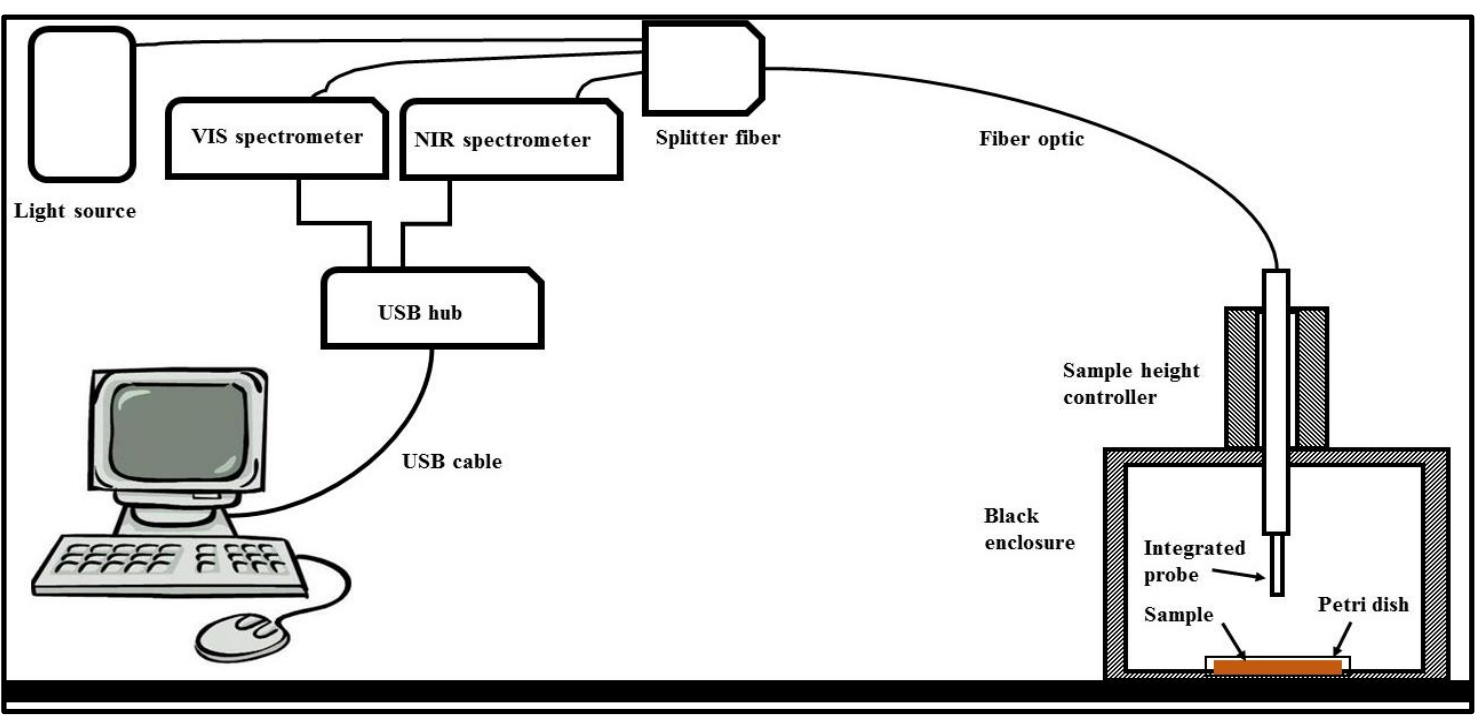

Figure 2. Schematic diagram of the UV-VIS-NIR spectroscopic system used to acquire spectral information for carrot roots 


\subsection{Measurement of Quality Attributes of Carrots}

\subsubsection{Color Measurement}

Samples color was measured in the CIELAB color space (Commission Internationale de l'Eclairage) where $L^{*}$ represents lightness $(0-100), a^{*}$ represents red/green coordinate, and $b^{*}$ represents yellow/blue coordinate (McGuire, 1992). The color measurement was performed using the CR400 Chroma Meter (Konica Minolta, Chiyoda, Tokyo, Japan). For each carrot, six readings were recorded at different locations and the average value was reported.

\subsubsection{Firmness Measurement}

Firmness measurement was carried out using the TA-X7 plus texture analyzer (Stable Micro Systems, Godalming, Surrey GU7 1YL, United Kingdom). The outer surface of each sample was tested for firmness using the TA-10 probe (Stable Micro Systems, Godalming, Surrey GU7 1YL, United Kingdom) that has $12.5 \mathrm{~mm}$ diameter and $35 \mathrm{~mm}$ length. The experiment configurations included head speed of $1 \mathrm{~mm} \cdot \mathrm{s}^{-1}$ and a penetration depth of $5 \mathrm{~mm}$. The maximum force was recorded as the firmness in Newton. For each sample, firmness was measured at six different locations and the average value was reported.

\subsubsection{Moisture Content Measurement}

Moisture content was measured following the Association of Official Agricultural Chemists official method 984.25 (AOAC, 2010a). Samples were weighed, then dried in an air-forced convection oven at $105{ }^{\circ} \mathrm{C}$ for $16 \mathrm{~h}$ and the final weight was recorded. The final moisture content was calculated using the difference between samples weights before and after drying and the original sample weight before drying.

\subsubsection{Total Soluble Solids Measurement}

Total soluble solids (TSS) was measured using a digital refractometer (HI 96801, Woonsocket, RI, USA) and the TSS value was obtained in ${ }^{\circ}$ Brix unit.

\subsubsection{Vitamin C Measurement}

Estimation of Vitamin C in the carrot samples was performed using the AOAC official method 967.21 (AOAC, 2010 b) with slight modification. Metaphosphoric acid $\left(\mathrm{HPO}_{3}\right)$-acetic acid $\left(\mathrm{CH}_{3} \mathrm{COOH}\right), 1 \mathrm{~N}$, was used as an extraction solution and prepared by dissolving, with shaking, $15 \mathrm{~g}$ of $\mathrm{HPO}_{3}$ pellets in $40 \mathrm{~mL} \mathrm{CH}_{3} \mathrm{COOH}$ and 200 $\mathrm{mL}$ distilled water. The $\mathrm{HPO}_{3}-\mathrm{CH}_{3} \mathrm{COOH}$ solution was prepared before each experiment and stored at $10{ }^{\circ} \mathrm{C}$ for no longer than 7 days. Ascorbic acid (AA) standard, $1 \mathrm{mg} \cdot \mathrm{mL}^{-1}$ was prepared by dissolving $50 \mathrm{mg}$ of ascorbic acid reference standard into $50 \mathrm{~mL}$ of $\mathrm{HPO}_{3}-\mathrm{CH}_{3} \mathrm{COOH}$. Indophenol solution (dye) was prepared by dissolving $50 \mathrm{mg}$ of 2,6-dichloroindophenol in $\mathrm{NaHCO}_{3}$ solution (prepared by dissolving $42 \mathrm{mg}$ in $50 \mathrm{~mL}$ of distilled water) and dilute to $200 \mathrm{~mL}$ using $\mathrm{HPO}_{3}-\mathrm{CH}_{3} \mathrm{COOH}$. Each sample, $10 \mathrm{~g}$, was first crushed of sample using a mortar and pestle, then blended with $50 \mathrm{~mL}$ of $\mathrm{HPO}_{3}-\mathrm{CH}_{3} \mathrm{COOH}$ for $1 \mathrm{~min}$, then diluted into $100 \mathrm{~mL}$ and filtered. Titration process was conducted using three-50 mL flasks for each sample. For standard replicates, $5 \mathrm{~mL}$ of $\mathrm{HPO}_{3}-\mathrm{CH}_{3} \mathrm{COOH}$ was added to $2 \mathrm{~mL}$ of standard AA then titrated using the dye until distinct rose color lasts for $5 \mathrm{~s}$ or longer. For blank replicates, $7 \mathrm{~mL}$ of $\mathrm{HPO}_{3}-\mathrm{CH}_{3} \mathrm{COOH}$ was added to a volume of distilled water equal to the average dye volume for standard titration then titrated. Each sample replicate was titrated by adding $5 \mathrm{~mL}$ of $\mathrm{HPO}_{3}-\mathrm{CH}_{3} \mathrm{COOH}$ to $2 \mathrm{~mL}$ of sample extract. Ascorbic acid content $\left(\mathrm{mg} .100 \mathrm{~g}^{-1}\right)$ was then estimated using the following equation:

$$
\text { Ascorbic acid }\left(\frac{m g}{100 g}\right)=(X-B) *\left(\frac{F}{E}\right) *\left(\frac{V}{Y}\right) * 100
$$

Where $\mathrm{X}$ and $\mathrm{B}$ are the dye volume for sample and blank respectively $(\mathrm{mL}), \mathrm{F}$ is the $\mathrm{mg}$ AA equivalent for $1 \mathrm{~mL}$ of dye. $\mathrm{E}$ is sample weight $(5 \mathrm{~g}), \mathrm{V}$ is the final volume of solution extracted from sample $(\mathrm{mL}), \mathrm{Y}$ is the sample volume used in titration $(5 \mathrm{~mL})$. F value is calculated as follow:

$$
F=\frac{\text { weiht of AA in volume standard }(0.05 \mathrm{~g})}{\text { Volume of prepared standard }(50 \mathrm{~g}) *(S-B)} * \text { volume of standard used in titration }(2 \mathrm{~mL})
$$

where $\mathrm{S}$ is the dye volume for standard $(\mathrm{mL})$.

\subsection{6 $\beta$-carotene Measurement}

Evaluation of $\beta$-carotene was conducted using the spectroscopy technique described by Scott (2001). Around 10 $\mathrm{g}$ of carrot, $3 \mathrm{~g}$ celite and $25 \mathrm{~mL}$ of cold acetone were poured into a clean mortar and the mixture was crushed 
until a coarse paste was formed. The crushed mixture was then filtered using a Buchner funnel (lined with Whatman \#1 filter paper) attached to a $500 \mathrm{~mL}$ flask wrapped in aluminum foil. The extraction and filtration process was repeated five times until a colorless extract was obtained and the residue was white. The mortar and pestle were washed with $10 \mathrm{~mL}$ of acetone and the rinsate passed through the funnel. The filtrate was added slowly to a $500 \mathrm{~mL}$ separatory funnel with $40 \mathrm{~mL}$ petroleum ether (PE). Deionized water $(300 \mathrm{~mL})$ was added slowly via the sides of the separatory funnel without shaking. The apparatus was sit for 15 min before discarding the lower phase. This process was repeated 3 times adding $\approx 200 \mathrm{~mL}$ of deionized water (Nanopure diamond) each time. In the last washing the lower phase was discarded completely. The upper phase was collected in a round bottom flask after passing it through $15 \mathrm{~g}$ of $\mathrm{Na}_{2} \mathrm{SO}_{4}$. The separator funnel was then washed with $3 \mathrm{~mL}$ of petroleum ether and also passed through the funnel with $\mathrm{Na}_{2} \mathrm{SO}_{4}$. The PE extract was concentrated using rotary evaporator (Buch model R-215) at $35^{\circ} \mathrm{C}$ without rotation. After $15 \mathrm{~min}$ the extract was then dried using a gentle ultra-high pure $\mathrm{N}_{2}$ stream. The sample was then re-dissolved in $4 \mathrm{~mL}$ petroleum ether and filtered through a 0.5 $\mu \mathrm{m}$ PTFE syringe filter into a dry cuvette. $\beta$-carotene standard in petroleum ether was prepared using a serial dilution. $0.01 \mathrm{~g}$ of Type $1 \beta$-carotene $\geqslant 93 \%$ (Sigma C9750) standard was added to $10 \mathrm{~mL}$ of PE in a clean 125 $\mathrm{mL}$ bottle wrapped in aluminum foil. The solution was made up to a $100 \mathrm{~mL}$ using PE and filtered through a 0.5 $\mu \mathrm{m}$ PTFE filter. This solution was successively diluted to obtain 1-7 $\mu \mathrm{g} \cdot \mathrm{mL}^{-1} \beta$-carotene standards. A standard curve was obtained by measuring the absorbance at $450 \mathrm{~nm}$ of each standard solution using a spectrophotometer (Genesys 10S UV-Vis, Thermo Fisher Scientific, Waltham, MA, USA) and plotting against its respective concentration. Samples were diluted appropriately to achieve absorbance readings in the linear portion using Beer-Lamberts law. The total carotenoid content was calculated using the formula:

$$
\beta-\text { Carotene content }\left(\frac{\mu g}{100 g}\right)=\frac{A \times V(m l) \times 10^{4}}{A^{1 \%} \times P(g)} \times 100
$$

Where $\mathrm{A}$ is the absorbance, $\mathrm{V}$ is the total extract volume $(\mathrm{mL}), \mathrm{A}^{1 \%}$ is the absorbance at a given wavelength of a $1 \%$ solution in $1 \mathrm{~cm}$ light-path spectrophotometer cuvette, $\mathrm{P}$ is the sample weight $(\mathrm{g})$.

\subsection{Data Analysis}

Partial least squares regression (PLSR) was implemented to obtain calibration models for quality attributes studied. PLSR is known for its capability of handling collinear data such as that obtained from spectroscopic systems (Varmuza \& Filzmoser, 2009). The SIMPLS algorithm version of PLSR created by De Jong (1993) was used. Noise associated with spectroscopic signals is somewhat common. Such noise results from electronic components (i.e. A/D converter, detector), scatters from samples, or yielded from sample variation (Varmuza \& Filzmoser, 2009). Thus, it is often necessary to pretreat spectroscopic data before building the calibration model. Several preprocessing techniques were then applied to the raw spectroscopic data including, in addition to non-processed data, smoothing using first derivative, smoothing using second derivative, multiplicative signal correction (MSC), standard normal variate (SNV), normalization, and weighted baseline. Data was divided into a calibration set ( $80 \%$ of the data) and prediction set (20\% of the data). Preprocessing was conducted on two stages as stated by Rady, Guyer, Kirk, \& Donis-González (2014). A 4-fold cross validation technique was performed on the calibration set to choose the optimal calibration model based on the root mean square error of cross validation (RMSEcv) for the calibration model. The optimal calibration model was then applied on the separate set of data to obtain the best prediction model based on the root mean square error of prediction (RMSEP) and the ratios of performance to deviation (RPD).

Reducing the number of wavelengths (independent variables) in the calibration models developed by the PLSR technique has the advantage of minimizing both interfering wavelengths and computational time (Heise \& Winzen, 2002). Additionally, in relatively high dimensional data such as spectroscopic spectra, using selected variables in building calibration models helps overcome overfitting and collinearity problems, hence, more robust models can be obtained (Benoudjit, Cools, Meurens, \& Verleysenet, 2004). In this study, the interval partial least squares (IPLS) method was utilized to obtain the most influencing wavelengths. IPLS implements a sequential and exhaustive algorithms to deduce the optimum subset of variables (Rady \& Guyer, 2015; Ekramirad, Rady, Adedeji, \& Alimardani, 2017). Based on preliminary analysis, the applied IPLS method in this study contained the following configurations: sequential forward mode, window width value of 1 variable, and 15 latent variables.

\section{Results and Discussion}

\subsection{Distribution of Constituents and Spectral Data}

The summary of several descriptive statistics for the measured quality attributes for Nectar carrot roots is shown 
in Table 1. The level of Vitamin C from this study are lower than those reported by Favell (1998) who reported values of $3.7-4.4 \mathrm{mg} / 100 \mathrm{~g}$. Values of $\beta$-carotene in this study were less than those stated in some former studies (Zude et al., 2007; Quilitzsch et al., 2005) and higher than those stated by Krähmer et al. (2016). Values of the color space, $L^{*}, a^{*}$, and $b^{*}$ show a strong orange color for samples illustrated by the positive values of $a^{*}$ (more into red color) and $b^{*}$ (more yellowness). Values of color parameters deduced in this study showed similar values to those reported by Zieliñska, Zapotoczny, \& Markowski (2005). Firmness values demonstrated significantly higher hardness than previous studies in contrast to TSS and moisture content values that were close to what stated in the literature (Favell, 1998). Differences between the values of various attributes obtained in this study and those listed in the literatures mainly resulted from the difference in cultivars, growing conditions and sampling procedures.
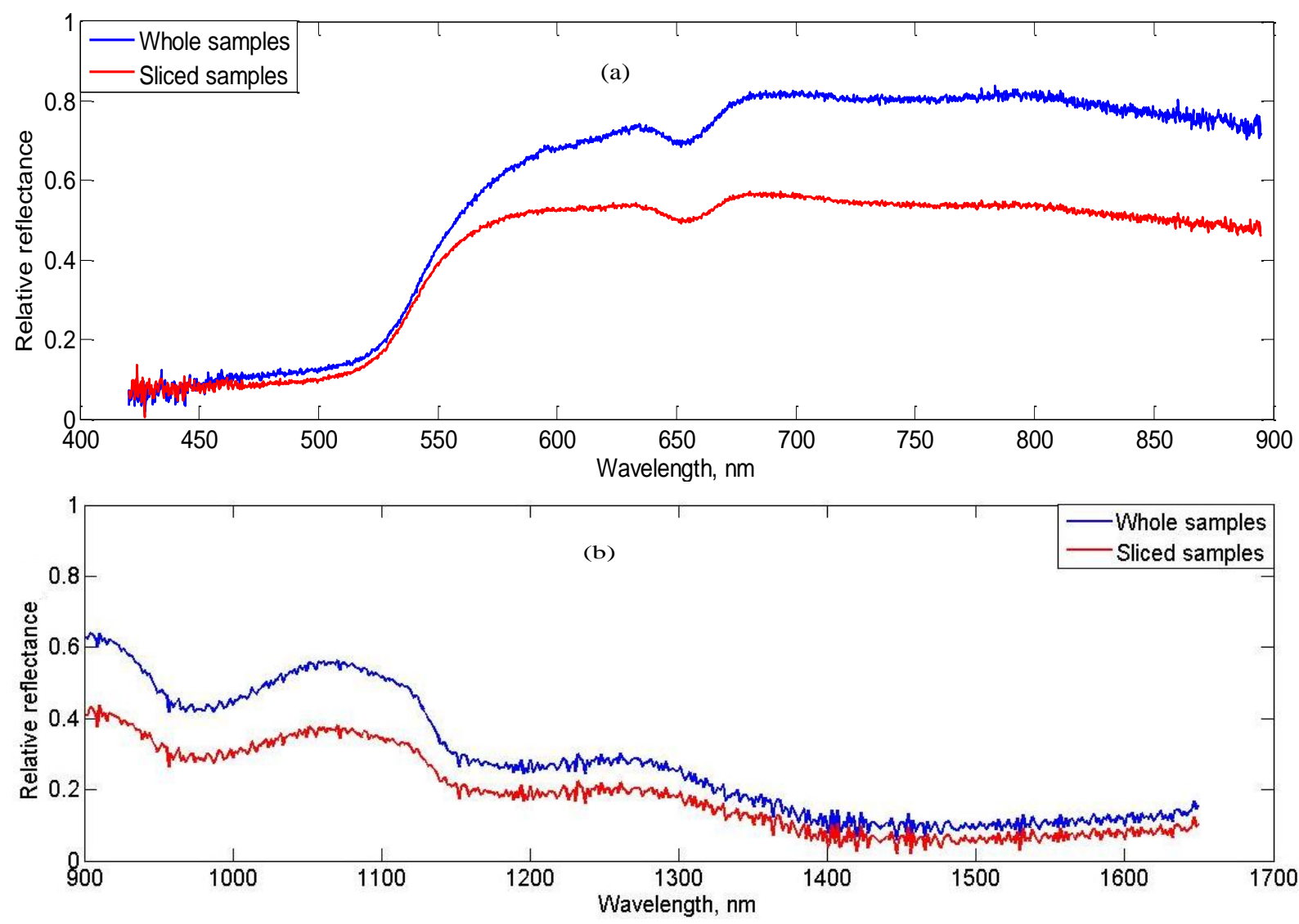

Figure 3. Average reflectance spectra for carrot samples after scanned using spectroscopic system in a) Vis-NIR region and b) NIR region

Table 1. Summary of the measured quality attributes of carrot roots (cv. Nectar)

\begin{tabular}{ll}
\hline Carrot characteristics & Mean \pm standard deviation \\
\hline $\mathrm{L}^{*}$ & $51.78 \pm 2.00$ \\
$\mathrm{a}^{*}$ & $18.10 \pm 1.79$ \\
$\mathrm{~b}^{*}$ & $41.65 \pm 2.52$ \\
Firmness $(\mathrm{N})$ & $116.00 \pm 12.75$ \\
Total soluble solids (oBrix) & $10.59 \pm 1.39$ \\
Moisture content $(\%$ wet basis) & $88.08 \pm 1.94$ \\
Vitamin $\mathrm{C}(\mathrm{mg} / 100 \mathrm{~g})$ & $0.90 \pm 0.52$ \\
$\beta$-carotene $(\mu \mathrm{g} / 100 \mathrm{~g})$ & $1907.8 \pm 484.1$ \\
\hline
\end{tabular}

The relative reflectance data acquired from the carrot roots of the whole and sliced samples in the Vis-NIR and NIR regions are shown in Fig. 3a-b. In general, whole roots resulted in higher relative reflectance values than sliced samples in Vis-NIR and NIR regions which is possibly due to the relatively non-uniform surface of the whole roots compared to the slices which yielded more interfering spectra and consequently less absorbed light in the former case (i.e. more reflected light). In the case of Vis-NIR region, it was found that only the spectra in 
the range of 420-895 nm (1901 wavelengths) can be considered valuable for further analysis. An absorption peak was observed around $470 \mathrm{~nm}$ which has been stated to be related to the carotenes pigment (Liu et al., 2016). Another absorption peak was observed around $650 \mathrm{~nm}$ which is due to absorption of chlorophyll II (Zude et al., 2007). In the case of NIR range, only the spectra in the range of 900-1650 nm (470 wavelengths) were carried out to the next level of analysis due to the considerable noise levels outside that range. Several absorption peaks were observed around 970, 1200, and $1470 \mathrm{~nm}$ which were due to the O-H stretching overtone related to moisture content (Liu et al., 2016; Workman \& Weyer, 2008). It was also observed that NIR spectra showed more ripples than the Vis-NIR spectra which illustrated the need for spectral preprocessing.

\subsection{Results of PLSR Models Using All Effective Wavelengths}

The optimal PLSR prediction models obtained are shown in Tables 2 and 3, using all effective wavelengths mentioned in section 3.1, and Tables 4-5 using selected wavelengths. The best models are shown by shading in all the tables. In the case where all effective wavelengths were used, it was noted that $L^{*}$ color parameter and $\beta$-carotene were not efficiently predicted. In the case of whole samples, data obtained from the Vis-NIR sensor yielded the best prediction models having r(RPD) values of 0.51(0.67) for firmness, 0.90(1.49) for TSS, and $0.74(1.47)$ for Vitamin C. Whereas, the data obtained from the NIR sensor yielded the best prediction models for $a^{*}(\mathrm{r}(\mathrm{RPD})=0.84(0.88)), b *(\mathrm{r}(\mathrm{RPD})=0.86(2.07))$, and moisture content $(\mathrm{r}(\mathrm{RPD})=0.92(1.76))$. In the case of the sliced samples, the majority of quality attributes of the prediction models were best predicted using the NIR sensor and the prediction performance was close to that obtained for the whole roots. The best prediction models for $L^{*}, a^{*}, b^{*}$, firmness, and moisture content were obtained from the NIR data with (RPD) values of 0.50(0.73), $0.71(0.86)$, and $0.78(1.68), 0.69(0.66)$, and $0.97(1.44)$, respectively. Whereas, the best models for TSS, Vitamin $\mathrm{C}$, and $\beta$-carotene were yielded using the Vis-NIR data with $\mathrm{r}(\mathrm{RPD})$ values of $0.87(1.55), 0.74(1.47)$, and $0.92(1.76)$, respectively. It is worth stating that color parameters significantly indicate the presence and variation of pigments in carrots (Liu et al., 2016; Zude et al., 2007).

Table 2. Results of the PLSR for the best prediction models using all effective wavelengths for predicting several quality attributes of whole carrot samples scanned by Vis-NIR and NIR spectroscopic sensors (shaded rows represent prediction models with better performance)

\begin{tabular}{|c|c|c|c|c|c|c|c|}
\hline \multirow[t]{2}{*}{ Sensor } & \multirow[t]{2}{*}{ Attribute (Y) } & \multirow{2}{*}{$\begin{array}{l}\text { Preprocessing method for: spectral data } \\
\text { in stage } 1 \text {, stage } 2 \text {, and for attribute (Y) }\end{array}$} & \multicolumn{2}{|c|}{ Calibration model $^{\mathrm{a}}$} & \multicolumn{3}{|c|}{ Prediction model } \\
\hline & & & $\mathbf{r}_{\mathrm{cal}}$ & $\mathbf{R M S E}_{\mathrm{cv}}$ & $\mathbf{r}_{\mathrm{p}}$ & $\mathbf{R M S E}_{\mathrm{p}}$ & $\mathbf{R P D}_{\mathrm{p}}$ \\
\hline \multirow[t]{8}{*}{ Vis-NIR } & $L^{*}$ & Median, $1^{\text {st }}$ derivative, no & 0.72 & 3.09 & 0.33 & 2.92 & 0.76 \\
\hline & $a^{*}$ & Median, $1^{\text {st }}$ derivative, no & 0.86 & 3.05 & 0.71 & 1.25 & 1.02 \\
\hline & $b^{*}$ & Median, $2^{\text {nd }}$ derivative, power & 0.83 & 4.05 & 0.75 & 1.93 & 1.25 \\
\hline & Firmness $(\mathrm{N})$ & Mean, Weighted baseline, no & 0.59 & 0.12 & 0.51 & 0.14 & 0.67 \\
\hline & Moisture content (\%wb) & Median, $2^{\text {nd }}$ derivative, no & 0.77 & 1.04 & 0.46 & 3.51 & 1.09 \\
\hline & TSS $\left({ }^{\circ}\right.$ Brix $)$ & Median, median, power & 1.00 & 0.07 & 0.90 & 0.03 & 1.49 \\
\hline & Vitamin $C(\mu \mathrm{g} / \mathrm{g})$ & Median, $2^{\text {nd }}$ derivative, no & 0.78 & 0.74 & 0.74 & 0.44 & 1.47 \\
\hline & $\beta$-carotene $(\mu \mathrm{g} / 100 \mathrm{~g})$ & Median, median, log & 0.65 & 0.39 & 0.25 & 0.40 & 1.07 \\
\hline \multirow[t]{8}{*}{ NIR } & $L^{*}$ & Median, $1^{\text {st }}$ derivative, no & 0.68 & 3.19 & 0.43 & 1.64 & 0.89 \\
\hline & $a^{*}$ & Median, no, no & 0.99 & 0.10 & 0.84 & 0.11 & 0.88 \\
\hline & $b^{*}$ & Median, no, no & 1.00 & 3.10 & 0.86 & 1.24 & 2.07 \\
\hline & Firmness (N) & Median, no, log & 0.45 & 0.14 & 0.24 & 0.13 & 0.61 \\
\hline & Moisture content (\%wb) & Median, snv, no & 0.81 & 1.12 & 0.58 & 3.94 & 0.97 \\
\hline & TSS $\left({ }^{\circ}\right.$ Brix $)$ & Median, normalization, no & 0.99 & 2.41 & 0.62 & 1.26 & 0.85 \\
\hline & Vitamin C $(\mu \mathrm{g} / \mathrm{g})$ & Medina, no, log & 0.94 & 0.51 & 0.71 & 0.70 & 0.73 \\
\hline & $\beta$-carotene $(\mu \mathrm{g} / 100 \mathrm{~g})$ & Median, $2^{\text {nd }}$ derivative, $\log$ & 0.44 & 0.40 & 0.28 & 0.42 & 1.04 \\
\hline
\end{tabular}

\footnotetext{
${ }^{\mathrm{a}} \mathrm{r}_{\text {cal }}$ : correlation coefficient for calibration, $\mathrm{r}_{\mathrm{p}}$ : correlation coefficient for prediction model, RMSEcv: root mean square of error for calibration using cross validation, RMSEp: root mean square of error for prediction, $\mathrm{RPD}_{\mathrm{p}}$ : ratio between performance to deviation for prediction.
} 
Table 3. The results of PLSR for the best prediction models with all effective wavelengths for predicting listed quality attributes of sliced carrots scanned with Vis-NIR and NIR spectroscopic sensors (shaded rows represent prediction models with better performance)

\begin{tabular}{|c|c|c|c|c|c|c|c|}
\hline \multirow[t]{2}{*}{ Sensor } & \multirow[t]{2}{*}{ Attribute (Y) } & \multirow{2}{*}{$\begin{array}{l}\text { Preprocessing method for: spectral data } \\
\text { in stage } 1, \text { stage } 2, \& \text { for attribute }(Y)\end{array}$} & \multicolumn{2}{|c|}{ Calibration model $^{\mathbf{a}}$} & \multicolumn{3}{|c|}{ Prediction model } \\
\hline & & & $\mathbf{r}_{\text {cal }}$ & $\mathrm{RMSE}_{\mathrm{cv}}$ & $\mathbf{r}_{\mathrm{p}}$ & $\mathbf{R M S E}_{\mathrm{p}}$ & $\mathbf{R P D}_{\mathrm{p}}$ \\
\hline \multirow[t]{8}{*}{ Vis-NIR } & $L^{*}$ & Median, $1^{\text {st }}$ derivative, $\log$ & 0.72 & 0.06 & 0.34 & 0.06 & 0.74 \\
\hline & $a^{*}$ & Median, $1^{\text {st }}$ derivative, $\log$ & 0.88 & 0.17 & 0.69 & 0.08 & 0.94 \\
\hline & $b^{*}$ & Median, $2^{\text {nd }}$ derivative, no & 0.83 & 4.05 & 0.75 & 1.93 & 1.25 \\
\hline & Firmness (N) & Mean, $1^{\text {st }}$ derivative, no & 0.67 & 10.42 & 0.53 & 14.06 & 0.64 \\
\hline & Moisture content (\%wb) & Median, $2^{\text {nd }}$ derivative, no & 0.77 & 1.04 & 0.46 & 3.51 & 1.09 \\
\hline & TSS $\left({ }^{\circ}\right.$ Brix $)$ & Mean, median, no & 1.00 & 1.30 & 0.87 & 0.55 & 1.55 \\
\hline & Vitamin $C(\mu \mathrm{g} / \mathrm{g})$ & Median, $2^{\text {nd }}$ derivative, no & 0.78 & 0.74 & 0.74 & 0.44 & 1.47 \\
\hline & $\beta$-carotene $(\mu \mathrm{g} / 100 \mathrm{~g})$ & Median, median, log & 0.97 & 0.35 & 0.92 & 0.24 & 1.76 \\
\hline \multirow[t]{8}{*}{ NIR } & $L^{*}$ & Mean, no, no & 0.58 & 0.04 & 0.50 & 0.06 & 0.73 \\
\hline & $a^{*}$ & Median, median, no & 0.86 & 3.05 & 0.71 & 1.02 & 0.86 \\
\hline & $b^{*}$ & Median, $2^{\text {nd }}$ derivative, power & 1.00 & 0.08 & 0.78 & 0.03 & 1.68 \\
\hline & Firmness (N) & Median, $2^{\text {nd }}$ derivative, $\log$ & 1.00 & 0.10 & 0.69 & 0.12 & 0.66 \\
\hline & Moisture content $(\%$ wb) & Median, $2^{\text {nd }}$ derivative, $\log$ & 1.00 & 0.01 & 0.97 & 0.03 & 1.44 \\
\hline & TSS $\left({ }^{\circ}\right.$ Brix $)$ & Median, snv, log & 0.56 & 0.11 & 0.40 & 0.09 & 1.12 \\
\hline & Vitamin C ( $\mu \mathrm{g} / \mathrm{g})$ & Medina, median, log & 1.00 & 0.55 & 0.72 & 0.39 & 1.54 \\
\hline & $\beta$-carotene $(\mu \mathrm{g} / 100 \mathrm{~g})$ & Mean, no, log & 0.85 & 0.33 & 0.82 & 0.23 & 1.86 \\
\hline
\end{tabular}

${ }^{\mathrm{a}} \mathrm{r}_{\text {cal }}$ : correlation coefficient for calibration, $\mathrm{r}_{\mathrm{p}}$ : correlation coefficient for prediction model, RMSEcv: root mean square of error for calibration using cross validation, RMSEp: root mean square of error for prediction, $\mathrm{RPD}_{\mathrm{p}}$ : ratio between performance to deviation for prediction.

The performance of color prediction parameters in this study is comparable to that reported by Zude et al. (2007) that had $\mathrm{r}$ values of $0.51,0.55$, and 0.76 for $L^{*}, a^{*}$, and $b^{*}$, respectively. Firmness measurements are important for assessing the shelf life of stored carrot (Mastromatteo, Conte, \& Del Nobile, 2012). To our knowledge, no one has estimated carrot firmness, Vitamin C, or TSS using a noninvasive method using Vis-NIR spectroscopy with cross validation of test set. Results of moisture content are similar to those observed by Liu et al. (2016) in which the $\mathrm{r}$ value was as high as 0.99 which illustrates the efficacy of the current study for evaluating moisture content. The deduced values for $\beta$-carotene are comparable to those obtained by previous studies. Zude et al. (2007) reported $\mathrm{r}$ value of 0.98 using Vis-NIR $(350-1,100 \mathrm{~nm})$ or NIR $(800-1,700 \mathrm{~nm})$ spectroscopy, whereas Quilitzsch et al. (2005) obtained $0.94 \mathrm{r}$ value using FTIR spectrometer $(800-2500 \mathrm{~nm})$.

Table 4. PLSR results for the best prediction models from selected wavelengths used for predicting listed quality attributes of whole carrot samples scanned by Vis-NIR and NIR spectroscopic sensors (shaded rows represent prediction models with better performance)

\begin{tabular}{|c|c|c|c|c|c|c|c|}
\hline \multirow[t]{2}{*}{ System } & \multirow{2}{*}{$\begin{array}{l}\text { Attribute } \\
(\mathbf{Y})\end{array}$} & \multirow{2}{*}{$\begin{array}{l}\text { Preprocessing method for: spectral data } \\
\text { in stage 1, stage } 2 \text {, and for attribute (Y) }\end{array}$} & \multicolumn{2}{|c|}{ Calibration model $^{\mathrm{a}}$} & \multicolumn{3}{|c|}{ Prediction model } \\
\hline & & & $\mathbf{r}_{\mathrm{cal}}$ & $\mathrm{RMSE}_{\mathrm{cv}}$ & $\mathbf{r}_{\mathbf{p}}$ & $\mathbf{R M S E}_{\mathrm{p}}$ & $\mathbf{R P D}_{\mathrm{p}}$ \\
\hline \multirow[t]{8}{*}{ Vis-NIR } & $L^{*}$ & Median, normalization, power & 0.91 & 0.07 & 0.65 & 0.06 & 0.43 \\
\hline & $a^{*}$ & Median, no, log & 1.00 & 0.05 & 0.91 & 0.03 & 2.66 \\
\hline & $b^{*}$ & Median, weighted, log & 0.93 & 0.04 & 0.32 & 0.10 & 0.62 \\
\hline & Firmness (N) & Median, median, power & 1.00 & 0.08 & 0.98 & 0.02 & 4.80 \\
\hline & Moisture content ( $\%$ wb) & Median, no, log & 0.89 & 0.04 & 0.80 & 0.03 & 1.62 \\
\hline & TSS $\left({ }^{\circ}\right.$ Brix $)$ & Median, no, log & 1.00 & 0.11 & 0.99 & 0.02 & 5.93 \\
\hline & Vitamin $C(\mu \mathrm{g} / \mathrm{g})$ & Median, median, no & 1.00 & 0.26 & 0.98 & 0.11 & 4.16 \\
\hline & $\beta$-carotene $(\mu \mathrm{g} / 100 \mathrm{~g})$ & Median, msc, power & 0.99 & 0.55 & 0.97 & 0.25 & 4.51 \\
\hline \multirow[t]{8}{*}{ NIR } & $L^{*}$ & Median, $2^{\text {nd }}$ derivative, power & 0.93 & 0.07 & 0.52 & 0.06 & 0.49 \\
\hline & $a^{*}$ & Median, median, log & 1.00 & 0.08 & 0.89 & 0.05 & 1.83 \\
\hline & $b^{*}$ & Median, median, no & 1.00 & 2.03 & 0.98 & 0.44 & 5.85 \\
\hline & Firmness (N) & Mean, median, power & 1.00 & 0.10 & 0.97 & 0.04 & 2.45 \\
\hline & Moisture content (\%wb) & Median, no, log & 0.99 & 0.01 & 0.75 & 0.03 & 1.47 \\
\hline & TSS $\left({ }^{\circ}\right.$ Brix $)$ & Median, median, log & 0.96 & 0.19 & 0.86 & 0.08 & 1.27 \\
\hline & Vitamin $C(\mu \mathrm{g} / \mathrm{g})$ & Medina, , msc, no & 0.95 & 0.68 & 0.82 & 0.26 & 1.73 \\
\hline & $\beta$-carotene $(\mu \mathrm{g} / 100 \mathrm{~g})$ & Median, no, power & 0.99 & 0.43 & 0.97 & 0.39 & 2.92 \\
\hline
\end{tabular}

$\mathrm{r}_{\mathrm{cal}}$ : correlation coefficient for calibration, $\mathrm{r}_{\mathrm{p}}$ : correlation coefficient for prediction model, RMSEcv: root mean square of error for calibration using cross validation, RMSEp: root mean square of error for prediction, $\mathrm{RPD}_{\mathrm{p}}$ : ratio between performance to deviation for prediction. 


\subsection{Results of PLSR Models Using Selected Wavelengths}

After including only the selected wavelengths, results for the best prediction models are shown in Tables 4-5 for whole and sliced samples. While prediction models for $L^{*}$ and moisture content were not considerably improved, it was obvious that most quality parameters evaluated in this study were significantly improved. For whole tubers, prediction of $b^{*}$ was best achieved by NIR sensor with r(RPD) values of $0.98(5.85)$, whereas, the Vis-NIR sensor secured the optimal prediction models for $a^{*}$, firmness, TSS, Vitamin C, and $\beta$-carotene with $\mathrm{r}(\mathrm{RPD})$ values of 0.91(2.66), 0.98(4.80), 0.99(5.93), 0.98(4.16), and 0.97(4.51), respectively. Better performance for prediction models for sliced samples was also noticed when using selected wavelengths. Color parameters were best predicted using the NIR sensor with $\mathrm{r}(\mathrm{RPD})$ values of 0.92(1.97), 0.96(2.83), and 0.86(1.25) for $L^{*}, a^{*}$, and $b^{*}$, respectively. The Vis-NIR sensor, however, yielded the best prediction models for other parameters with r(RPD) values of 0.99(6.65), 0.98(3.91), 0.97(2.03), 0.98(4.05), and 0.98(4.43) for firmness, moisture content, TSS, Vitamin C, and $\beta$-carotene respectively. Liu et al. (2016) used a multispectral imaging system to evaluate several quality parameters during carrot drying. The wavelengths implemented in such study had close value to those obtained in the current study using IPLS. In the case of the Vis-NIR sensor, wavelengths selected for the color parameters and firmness for the sliced samples showed close values to those used by Liu et al. (2016). Whereas for whole roots, all studied quality attributes except Vitamin $\mathrm{C}$ showed close values for selected wavelengths to the aforementioned study. In the case of the NIR sensor, fewer wavelength showed common trend with the previous study compared to the Vis-NIR sensor with Firmness and Vitamin C having such similarity for the sliced samples, and the firmness, $a^{*}$, and moisture content for the whole roots.

Table 5. The results of PLSR for the best prediction models using selected wavelengths for predicting several quality attributes of sliced carrot samples scanned with Vis-NIR and NIR spectroscopic sensors (shaded rows represent prediction models with better performance)

\begin{tabular}{|c|c|c|c|c|c|c|c|}
\hline \multirow{2}{*}{$\begin{array}{l}\text { System } \\
\text { type }\end{array}$} & \multirow{2}{*}{$\begin{array}{l}\text { Attribute } \\
(\mathbf{Y})\end{array}$} & \multirow{2}{*}{$\begin{array}{l}\text { Preprocessing method for: spectral data } \\
\text { in stage } 1 \text {, stage } 2 \text {, and for attribute }(Y)\end{array}$} & \multicolumn{2}{|c|}{ Calibration model $^{\mathrm{a}}$} & \multicolumn{3}{|c|}{ Prediction model } \\
\hline & & & $\mathbf{r}_{\text {cal }}$ & $\mathbf{R M S E}_{\mathrm{cv}}$ & $\mathbf{r}_{\mathbf{p}}$ & $\begin{array}{l}\mathbf{R M} \\
\mathbf{S E}_{\mathrm{p}} \\
\end{array}$ & $\mathbf{R P D}_{\mathrm{p}}$ \\
\hline Vis-NI & $L^{*}$ & Mean, weighted baseline, power & 1.00 & 0.04 & 0.81 & 0.09 & 0.45 \\
\hline \multirow[t]{7}{*}{$\mathbf{R}$} & $a^{*}$ & Median, weighted baseline, log & 0.99 & 0.10 & 0.59 & 0.26 & 0.27 \\
\hline & $b^{*}$ & Median, weighted baseline, log & 1.00 & 0.14 & 0.71 & 0.24 & 0.25 \\
\hline & Firmness (N) & Mean, no, power & 1.00 & 0.02 & 0.99 & 0.01 & 7.08 \\
\hline & Moisture content (\%wb) & Median, median, no & 1.00 & 1.61 & 0.98 & 0.98 & 3.91 \\
\hline & TSS $\left({ }^{\circ}\right.$ Brix $)$ & Median, median, no & 1.00 & 1.09 & 0.97 & 0.42 & 2.03 \\
\hline & Vitamin $C(\mu \mathrm{g} / \mathrm{g})$ & Median, no, power & 1.00 & 0.08 & 0.98 & 0.04 & 4.05 \\
\hline & $\beta$-carotene $(\mu \mathrm{g} / 100 \mathrm{~g})$ & Mean, no, $\log$ & 1.00 & 0.27 & 0.98 & 0.10 & 4.43 \\
\hline \multirow[t]{8}{*}{ NIR } & $L^{*}$ & Mean, no, power & 0.89 & 0.05 & 0.92 & 0.02 & 1.97 \\
\hline & $a^{*}$ & Median, no, power & 1.00 & 0.03 & 0.96 & 0.02 & 2.83 \\
\hline & $b^{*}$ & Median, no, log & 0.97 & 0.04 & 0.86 & 0.05 & 1.25 \\
\hline & Firmness (N) & Median, $2^{\text {nd }}$ derivative, log & 0.97 & 0.10 & 0.73 & 0.10 & 0.72 \\
\hline & Moisture content (\%wb) & Mean, $1^{\text {st }}$ derivative, $\log$ & 0.79 & 0.01 & 0.70 & 0.03 & 1.25 \\
\hline & TSS $\left({ }^{\circ}\right.$ Brix $)$ & Mean, median, log & 0.85 & 0.11 & 0.84 & 0.05 & 1.61 \\
\hline & Vitamin $C(\mu \mathrm{g} / \mathrm{g})$ & Medina, median, no & 0.90 & 0.90 & 0.85 & 0.35 & 1.83 \\
\hline & $\beta$-carotene $(\mu \mathrm{g} / 100 \mathrm{~g})$ & Mean, no, log & 0.92 & 0.34 & 0.97 & 0.14 & 3.15 \\
\hline
\end{tabular}

$\mathrm{r}_{\mathrm{cal}}$ : correlation coefficient for calibration, $\mathrm{r}_{\mathrm{p}}$ : correlation coefficient for prediction model, RMSEcv: root mean square of error for calibration using cross validation, RMSEp: root mean square of error for prediction, $\mathrm{RPD}_{\mathrm{p}}$ : ratio between performance to deviation for prediction

Table 6. Number of selected Wavelengths using IPLS for predicting quality attributes of carrot samples (whole and sliced) that were scanned using Vis-NIR and NIR sensors

\begin{tabular}{lcccc}
\hline \multirow{2}{*}{ Attribute } & \multicolumn{2}{c}{ Vis-NIR sensor } & \multicolumn{2}{c}{ NIR sensor } \\
\cline { 2 - 5 } & Whole samples & Sliced samples & Whole samples & Sliced samples \\
\hline$L^{*}$ & 16 & 19 & 24 & 10 \\
$a^{*}$ & 17 & 15 & 23 & 19 \\
$b^{*}$ & 11 & 17 & 17 & 11 \\
Firmness & 16 & 16 & 20 & 20 \\
Moisture content & 16 & 16 & 14 & 11 \\
TSS & 16 & 15 & 17 & 12 \\
Vitamin C & 17 & 17 & 13 & 14 \\
Beta-carotene & 16 & 19 & 12 & 15 \\
\hline
\end{tabular}

The number of wavelengths selected from each sensor to predict various constituent for sliced and whole 
samples are shown in Table 6. It was clearly shown that the wavelengths required to improve prediction models' performance were significantly decreased using the IPLS. The selected wavelengths from the Vis-NIR sensor for whole carrots were almost similar for all constituents. Whereas, those wavelengths were slightly larger in the case of sliced samples. In the case of the NIR sensor, selected wavelengths for whole roots were larger than for sliced samples for most constituents. Additionally, the selected wavelengths are also illustrated in Figure 4 for Vis/NIR system and Figure 5 for NIR system. In the case of Vis/NIR spectra, selected wavelengths for $\beta$-carotene showed agreement with results presented by Liu et al. (2016) where there was an absorption peak around $470 \mathrm{~nm}$ for sliced samples or whole roots. In the case of NIR spectra of sliced samples, selected wavelengths for moisture content included $1474 \mathrm{~nm}$ which is close to the common absorption peak of moisture $(1470 \mathrm{~nm})$ as showed by Zude, Birlouez-Aragon, Paschold, \& Rutledgem (2007). For whole roots, there was a selected wavelength of $968 \mathrm{~nm}$ which is also close to $970 \mathrm{~nm}$, the common absorption peak for water. Additionally, TSS-selected wavelengths include $1061 \mathrm{~nm}$ which is close to one of the wavelengths listed in the last study, $1054 \mathrm{~nm}$.
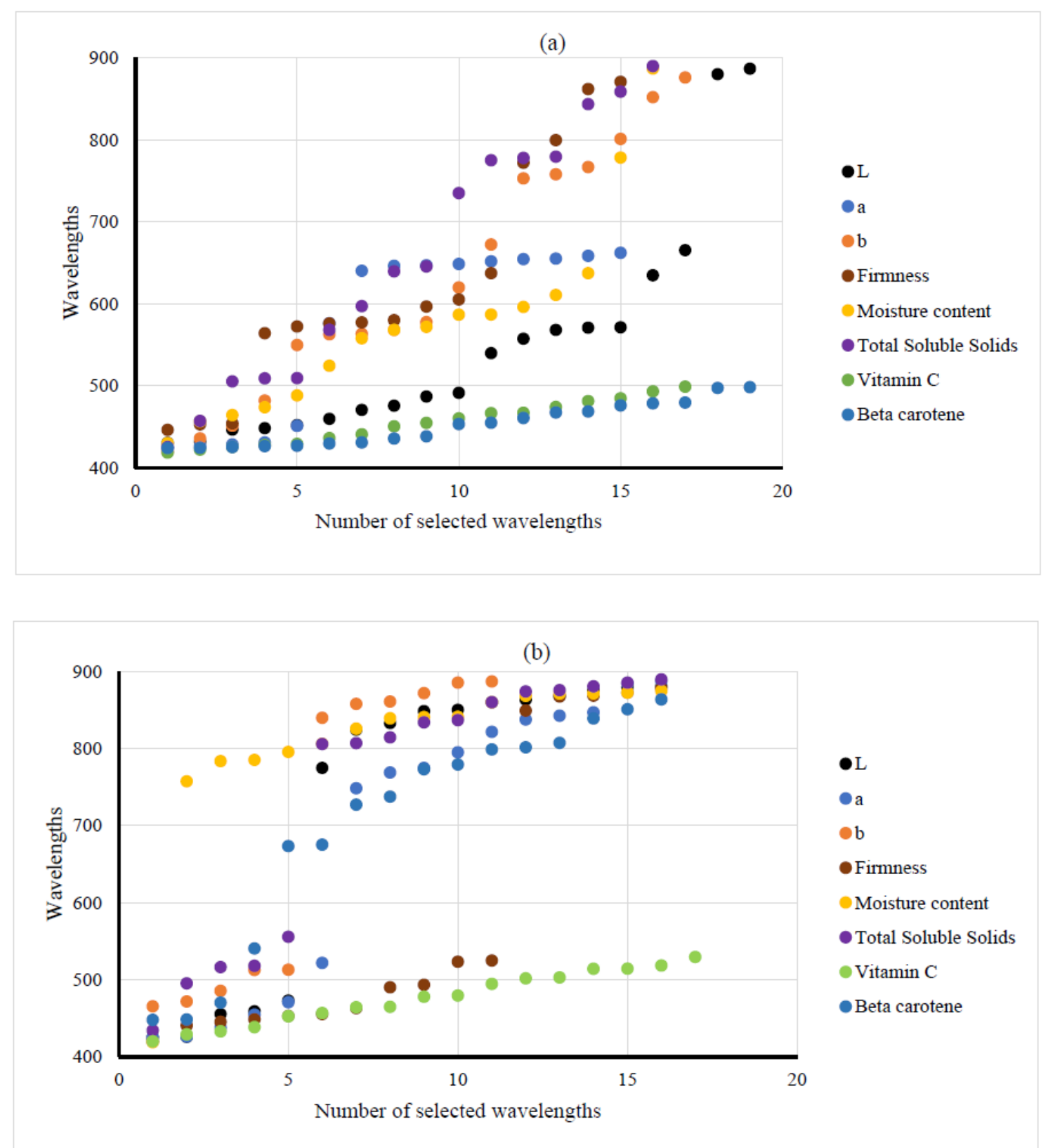

Figure 4. Number of selected wavelengths obtained using IPLS and Vis/NIR spectroscopy for different quality characteristics of carrot samples, a) sliced samples, b) whole roots 

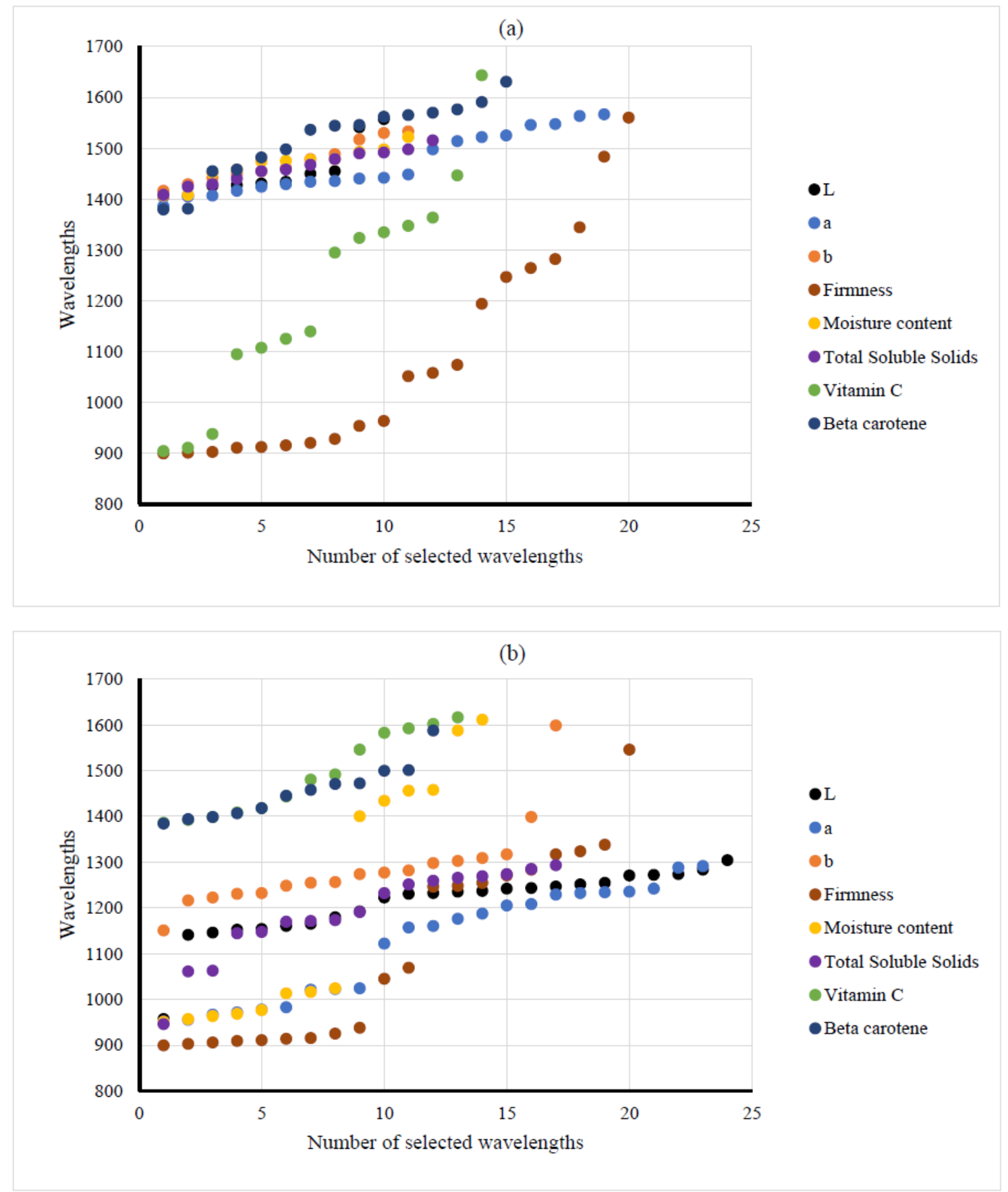

Figure 5. Number of selected wavelengths obtained using IPLS and NIR spectroscopy for different quality characteristics of carrot samples, a) sliced samples, b) whole roots

\section{Conclusions}

In this study, several quality characteristics of carrot roots were evaluated using spectroscopic data obtained from Vis-NIR and NIR sensors. Results obtained from the PLSR analysis proved the use of Vis-NIR spectroscopy as a noninvasive rapid method for quick and accurate estimation of quality constituents of carrots that are associated with aesthetic appeal for the consumers such as color, firmness, moisture content or those which are related to internal quality such as TSS, and micronutrients (Vitamin C and $\beta$-carotene). IPLS method allowed feature selection (the reduction of wavelengths associated with prediction) for each of the quality attribute. Obtaining high quality and nutritionally rich carrot juice is dependent on maintaining a high quality carrot roots during its supply chain. This is better done if there is a means for quick and continuous tracking of the physiological status 
and chemical constituent of the carrots after harvest, and shortly before processing. The approach proved in the study can serve that purpose. Future work will consider larger data set for model building with the possibility of increasing the robustness and stability of the prediction models.

\section{Acknowledgment}

The information reported in this paper (\#17-05-096) is part of a project of the Kentucky Agricultural Experiment Station and is published with the approval of the Director. The work was supported by the USDA National Institute of Food and Agriculture, Multistate project \#: 1007893.

\section{References}

Ahmad, M. H., Sahar, A., \& Hitzmann, B. (2017). Fluorescence spectroscopy for the monitoring of food processes, (Pp. 121-151). Springer, Cham. https://doi.org/10.1007/10_2017_11

Alasalvar, C., Al-Farsi, M., Quantick, P.C., Shahidi, F., \& Wiktorowicz, R. (2005). Effect of chill storage and modified atmosphere packaging (MAP) on antioxidant activity, anthocyanins, carotenoids, phenolics and sensory quality of ready-to-eat shredded orange and purple carrots. Food Chemistry, 89(1), 69-76. https://doi.org/10.1016/j.foodchem.2004.02.013

AOAC International. (2010a). Official Method 984.25. Moisture (loss of mass on drying) in frozen french-fried potatoes. AOAC International, Rockville, MD, USA.

AOAC International. (2010b). Official methods of analysis (18 th ed.). Current through revision 2 (On-line). AOAC International, Gaithersburg, MD, USA; 2005.

Becaro, A. A., Puti, F. C., Panosso, A. R., Gern, J. C., Brandão, H. M., Correa, D. S., \& Ferreira, M. D. (2016). Postharvest quality of fresh-cut carrots packaged in plastic films containing silver nanoparticles. Food and Bioprocess Technology, 9(4), 637-649. https://doi.org/10.1007/s11947-015-1656-z

Benoudjit, N., Cools, E., Meurens, M., \& Verleysen, M. (2004). Chemometric calibration of infrared spectrometers: selection and validation of variables by non-linear models. Chemometrics and Intelligent Laboratory Systems, 70(1), 47-53. https://doi.org/10.1016/j.chemolab.2003.10.008

Berger, M., Küchler, T., Maaßen, A., Busch-Stockfisch, M., \& Steinhart, H. (2008). Correlations of carotene with sensory attributes in carrots under different storage conditions. Food Chemistry, 106(1), 235-240. https://doi.org/10.1016/j.foodchem.2007.05.075

Burns, D. A., \& Ciurczak, E. W. (2007). Handbook of near-infrared analysis. CRC press.

De Jong, S. (1993). SIMPLS: an alternative approach to partial least squares regression. Chemometrics and Intelligent Laboratory Systems, 18(3), 251-263. https://doi.org/10.1016/0169-7439(93)85002-X

Demir, N., Acar, J., \& Bahçeci, K. S. (2004). Effects of storage on quality of carrot juices produced with lactofermentation and acidification. European Food Research and Technology, 218(5), 465-468. https://doi.org/10.1007/s00217-004-0883-8

Ekramirad, N., Rady, A., Adedeji, A. A., \& Alimardani, R. (2017). Application of hyperspectral imaging and acoustic emission techniques for apple quality prediction. Transactions of ASABE, 60(4), 1391-1401. https://doi.org/10.13031/trans.12184

Favell, D. J. (1998). A comparison of the vitamin C content of fresh and frozen vegetables. Food Chemistry, 62(1), 59-64. https://doi.org/10.1016/S0308-8146(97)00165-9

Food and Agriculture Organization (FAO). (2017). World and US carrot production in 2014 [Internet]. Available from: http://www.fao.org/faostat/en/\#data/QC. Accessed May 31, 2017.

Heise, H. M., \& Winzen, R. (2002). Fundamental chemometric methods. In: Siesler HW, Ozaki Y., Kawata S., Heise H.M., editors. Near Infrared Spectroscopy: Principles, Instruments, Applications, 125-162.

Keller, S., Löchte, T., Dippel, B., \& Schrader, B. (1993). Quality control of food with near-infrared-excited Raman spectroscopy. Fresenius' Journal of Analytical Chemistry, 346(6), 863-867. https://doi.org/10.1007/BF00321306

Klaiber, R. G., Baur, S., Koblo, A., \& Carle, R. (2005). Influence of washing treatment and storage atmosphere on phenylalanine ammonia-lyase activity and phenolic acid content of minimally processed carrot sticks. Journal of Agricultural and Food Chemistry, 53(4), 1065-1072. https://doi.org/10.1021/jf049084b

Krähmer, A., Böttcher, C., Rode, A., Nothnagel, T., \& Schulz, H. (2016). Quantifying biochemical quality parameters in carrots (Daucus carota L.)-FT-Raman spectroscopy as efficient tool for rapid metabolite 
profiling. Food Chemistry, 212, 495-502. https://doi.org/10.1016/j.foodchem.2016.05.176

Lawaetz, A. J., Christensen, S. M., Clausen, S. K., Jørnsgaard, B., Rasmussen, S. K., Andersen, S. B., \& Rinnan, Å. (2016). Fast, cross cultivar determination of total carotenoids in intact carrot tissue by Raman spectroscopy and partial least squares calibration. Food Chemistry, 204, 7-13. https://doi.org/10.1016/j.foodchem.2016.02.107

Liu, C., Liu, W., Lu, X., Chen, W., Yang, J., \& Zheng, L. (2016). Potential of multispectral imaging for real-time determination of colour change and moisture distribution in carrot slices during hot air dehydration. Food Chemistry, 195, 110-116. https://doi.org/10.1016/j.foodchem.2015.04.145

Luo, Y., Suslow, T., \& Cantwell, M. (2016). The commercial storage of fruits, vegetables, and florist and nursery stocks, ed. by R.E. Hardenburg, A.E. Watada, C.Y. Wang (ARS, USDA, USA).

Mastromatteo, M., Conte, A., \& Del Nobile, M. A. (2012). Packaging strategies to prolong the shelf life of fresh carrots (Daucus carota L.). Innovative Food Science \& Emerging Technologies, 13, 215-220. https://doi.org/10.1016/j.ifset.2011.10.010

McGuire, R. G. (1992). Reporting of objective color measurements. Horticultural Science, 27(12), 1254-1255.

Nicolle, C., Cardinault, N., Aprikian, O., Busserolles, J., Grolier, P., Rock, E., ... Rémésy, C. (2003). Effect of carrot intake on cholesterol metabolism and on antioxidant status in cholesterol-fed rat. European Journal of Nutrition, 42(5), 254-261. https://doi.org/10.1007/s00394-003-0419-1

Norris, K. H. Near-Infrared Spectroscopy-Past, Present, and Future. (1986). In: Cereal Foods World. American Association of Cereal Chemists. 3340 Pilot Knob Rd, St Paul, MN 55121-2097, Pp. 578-578.

Porep, J. U., Kammerer, D. R., \& Carle, R. (2015). On-line application of near infrared (NIR) spectroscopy in food production. Trends in Food Science \& Technology, 46(2), 211-230.

https://doi.org/10.1016/j.tifs.2015.10.002

Potter, A. S., Foroudi, S., Stamatikos, A., Patil, B. S., \& Deyhim, F. (2011). Drinking carrot juice increases total antioxidant status and decreases lipid peroxidation in adults. Nutrition Journal, 10(1), 96. https://doi.org/10.1186/1475-2891-10-96

Quilitzsch, R., Baranska, M., Schulzm H., \& Hoberg, E. (2005). Fast determination of carrot quality by spectroscopy methods in the UV-VIS, NIR and IR range. Journal of applied botany and food quality, 79(3), 163.

Rady, A. M., Guyer, D. E., Kirk, W., \& Donis-González, I. R. (2014). The potential use of visible/near infrared spectroscopy and hyperspectral imaging to predict processing-related constituents of potatoes. Journal of Food Engineering, 135, 11-25. https://doi.org/10.1016/j.jfoodeng.2014.02.021

Rady, A. M., \& Guyer, D. E. (2015). Evaluation of sugar content in potatoes using NIR reflectance and wavelength selection techniques. Postharvest Biology and Technology, 103, 17-26. https://doi.org/10.1016/j.postharvbio.2015.02.012

Schneider, B. (1997). In-vivo nuclear magnetic resonance spectroscopy of low-molecular-weight compounds in plant cells. Planta, 203(1), 1-8. https://doi.org/10.1007/s00050158

Schulz, H. (2014). Qualitative and Quantitative FT-Raman Analysis of Plants. In: Optical Spectroscopy and Computational Methods in Biology and Medicine. Springer, 253-278.

https://doi.org/10.1007/978-94-007-7832-0_9

Scott, K.J. (2001). Detection and measurement of carotenoids by UV/Vis spectrophotometry. Current protocols in food analytical chemistry. https://doi.org/10.1002/0471142913.faf0202s00

Seidel, K., Kahl, J., Paoletti, F., Birlouez, I., Busscher, N., Kretzschmar, U., ... \& Baiamonte, I. (2015). Quality assessment of baby food made of different pre-processed organic raw materials under industrial processing conditions. Journal of food science and technology, 52(2), 803-812. https://doi.org/10.1007/s13197-013-1109-5

Siesler, H. W. (2008). Introduction. In: Siesler HW, Ozaki Y, Kawata S, Heise HM, editors. Near-infrared spectroscopy: principles, instruments, applications. John Wiley \& Sons.

Simon, P. W., Freeman, R. E., Vieira, J. V., Boiteux, L. S., Briard, M., Nothnagel, T., ... Kwon, Y. S. (2008). Carrot. In: Vegetables II. Springer, 327-357. https://doi.org/10.1007/978-0-387-74110-9_8

Varmuza, K., \& Filzmoser, P. (2009). Introduction to multivariate statistical analysis in chemometrics. CRC 
press.

Workman Jr, J., \& Weyer, L. (2008). Practical guide to interpretive near-infrared spectroscopy. CRC press. https://doi.org/10.1201/9781420059496

Xu, X., Cheng, Y., Li, S., Zhu, Y., Xu, X., Zheng, X., ... Xie, L. (2014). Dietary carrot consumption and the risk of prostate cancer. European Journal of Nutrition, 53(8), 1615-1623. https://doi.org/10.1007/s00394-014-0667-2

Zieliñska, M., Zapotoczny, P., \& Markowski, M. (2005). Colour standard and homogenous groups of dried carrots of 34 commercial varieties. Polish Journal of Food and Nutrition Sciences, 14(1), 51-56.

Zude, M., Birlouez-Aragon, I., Paschold, P-J., \& Rutledgem, D. N. (2007). Non-invasive spectrophotometric sensing of carrot quality from harvest to consumption. Postharvest Biology and Technology, 45(1), 30-37. https://doi.org/10.1016/j.postharvbio.2007.01.010

\section{Copyrights}

Copyright for this article is retained by the author(s), with first publication rights granted to the journal.

This is an open-access article distributed under the terms and conditions of the Creative Commons Attribution license (http://creativecommons.org/licenses/by/4.0/). 